\title{
The Use of Intraosseous Screw for Upper Molar Distalization: A Case Report
}

\author{
Ömür Polat-Özsoya
}

\begin{abstract}
The use of implants has made a major change in orthodontic treatment mechanics. They have replaced conventional unaesthetic and compliance dependent extraoral appliances with well accepted intraoral mechanics. Implants can be used in molar and canine distalization, intrusion and in extraoral force applications. In the present case report, treatment of a case using an intermaxillary fixation screw (IMF) will be presented. The treatment results will be evaluated using pretreatment, post distalization and post treatment cephalometric radiographs and dental casts. (Eur J Dent 2008;2:115-1211
\end{abstract}

Key words: Implant; Molar distalization; Intraosseous screw; Anchorage.

\section{INTRODUCTION}

Anchorage control is a fundamental for successful orthodontic treatment. According to Newton's third law of motion, every action has an equaland opposite reaction. In clinicalorthodontics, stabilization of the anchorage unit should be made to prevent unwanted reactive tooth movements. Different extraoral and intraoral appliances have been used to preserve anchorage during tooth movement. ${ }^{1}$ However, while appliances like headgears require patient compliance, intraoral noncompliance appliances cause reciprocal tooth movement at the anchor unit. ${ }^{2-4}$

Since the successful improvements of

a Assistant Professor, University of Baskent, Faculty of Dentistry, Department of Orhodontics, Ankara, Turkey

- Corresponding author: Dr. Ömür Polat-Ozsoy Baskent Universitesi Dis Hekimligi Fakultesi

Ortodonti A. D., 11. sk. No:26 06490

Bahcelievler, Ankara TURKEY

Phone: +90-312-215 1336 Fax: +90-312-215 2962

Email: omurortolyahoo.com implant dentistry in the recent years, different bone anchors have made their use possible as anchorage in orthodontics. Osseointegrated implants, ${ }^{5-9}$ onplants $^{10}$ and intraosseous screws ${ }^{11}$ can be used as anchorage units in orthodontics. Osseointegrated implants need 3-6 months before loading. ${ }^{12}$ The somewhat complicated surgical procedure, discomfort during healing and the time needed for osseointegration are their main disadvantages. ${ }^{13}$

Due to the somewhat complex insertion and healing procedures of osseointegrated implants, some researchers investigated the success of the use of screws as temporary anchorage devices. Creekmore and Eklund used a vitallium screw below anterior nasal spine for upper incisor intrusion. ${ }^{14}$ The bone screw remained stable in 1 year period and was removed easily at the end of treatment. Researchers like Byloff et al, ${ }^{15}$ Karaman et $a l,{ }^{11}$ Gelgor et $a^{4}$ and Kircelli et $a^{16}$ have shown 
successful results using intraosseous screws for upper molar distalization. Screws can be used as direct anchorage unit that is connected directly to the teeth to be moved or anchorage teeth can be stabilized with the screw which acts as an indirect anchorage unit.

Gelgor et $\mathrm{al}^{4}$ have shown the results of 20 patients that had intraosseous screws used as an indirect anchorage unit to stabilize premolars for upper molar distalization. They used a titanium intraosseous screw, $1.8 \mathrm{~mm}$ in diameter and $14 \mathrm{~mm}$ in length as an indirect anchorage unit. The screw was placed in the anterior paramedian region of the palatal suture, $5 \mathrm{~mm}$ posterior to the incisive foramen and $3 \mathrm{~mm}$ lateral to the raphe. Upper first premolars were stabilized via a transpalatal arch that was connected to the screw. Distal force was applied to upper first molars using sectional arches and open nickel titanium coil springs between the stabilized premolars and upper first molars. According to the results of their study, the mean molar distalization was $3.9 \mathrm{~mm}$ with an average tipping of $8.7^{\circ}$ in 3 to 6.2 months. Despite their success in molar movement, the authors have not mentioned about the failure rate of the screws. Since the screws receive the distalization forces directly, the failure of the screws cannot be rare. This case report aims to demonstrate the treatment result of a dental Class II patient using an intraosseous screw for upper molar distalization. The distalization appliance presented here was supported by an acrylic Nance button to transmit the distalizing forces to the hard palate as well as the screw. The clinical and radiographic changes of both postdistalization stage and the end of treatment will be presented.

\section{CASE REPORT}

A 19 year old Caucasian female who had no history of significant medical problems or any family history of hereditary disease referred to our clinic with a chief complaint of upper midline deviation and palatally displaced upper right lateral incisor. Extraorally, the patient had a balanced facial profile and she had adequate gingival tissue on full smile (Figure 1).

Intraorally she had class I canine and molar relationships on left dentition and class II molar and canine relation on her right dentition. Upper midline deviation was $4 \mathrm{~mm}$ to the right and lower midline deviation was $2 \mathrm{~mm}$ to the right. Her left upper first molar had endodontic treatment and she also had big restorations on teeth 16, and 47 . Overjet was measured as $5 \mathrm{~mm}$ and overbite was 4 $\mathrm{mm}$. There was no transverse discrepancy (Figures 2 and 3). Temporomandibular joint showed no signs of clicks or crepitation, and the facial and masticatory muscles were asymptomatic.

Cephalometric evaluation showed that the patient had an SNA angle of $80.9^{\circ}$, an SNB angle of $79.5^{\circ}$, and an ANB angle of $1.4^{\circ}$. The mandibular plane (SN-GoMe) angle was $25.5^{\circ}$, the position of lower incisors were $22^{\circ}$ and $4 \mathrm{~mm}$ relative to the NA plane, and the position of upper incisors were $18^{\circ}$ and $4 \mathrm{~mm}$ relative to NA plane. The upper lip was $-5.0 \mathrm{~mm}$ behind $\mathrm{E}$ Plane and the lower lip was $-3 \mathrm{~mm}$ behind $\mathrm{E}$ plane. The nasolabial angle was $110^{\circ}$ (Figure 4) (Table 1). The pretreatment panoramic radiograph can be seen in Figure 5.

The treatment objectives included achievement of a Class I molar and canine relationships with distalization of the upper right molar. The treatment alternative comprised extraction however the patient refused any tooth extractions. Besides, her low SN-GoGn angle and increased overbite would complicate any extractions.

The patient preferred to have a distalization without any forms of extraoral appliance. Therefore the use of an intraoral distalization appliance that was supported by an intraosseous screw was planned. Prior to distalization, upper left third molar was extracted.

A titanium intraosseous screw lIMF intermaxillary screw, Stryker, Leibinger, Germanyl which is $2.0 \mathrm{~mm}$ in diameter and $14 \mathrm{~mm}$ in length was used as a bone anchor. Under local anesthesia, a 1.3-mm-diameter drill was used for primary stabilization of the screw. The screw was inserted in the anterior paramedian region of the palatal suture, 4-5 $\mathrm{mm}$ posterior to the incisive foramen and 3-4 $\mathrm{mm}$ lateral to the median line. Primary stabilization was assessed with a tweezer intraorally and screw position was checked by occlusal radiographs after insertion.

One week after screw insertion, impressions were obtained and a plaster model was prepared. The screw head was blocked out with wax. Occlusal wires extending to the anchor first premolars were bended from $0.8 \mathrm{~mm}$ wire and placed to the model. A self-cure acrylic was placed on to the screw, 
covering the extensions of the occlusal wires.

The appliance adaptation was checked clinically, and the occlusal wires were bonded to the upper first premolars using light-cure composite resin (Transbond XT, 3M Unitek, Monrovia, California). Bilateral sectional arches (0.016×0.022 inch) and 0.036 inch nickel-titanium open coil springs were inserted between the first premolar and the first molar with a continuous force of approximately $250 \mathrm{~g}$ per side (Figure 6). Lateral cephalometric radiograph taken at the end of distalization can be seen in Figure 7.

At the end of distalization, the acrylic plate was removed with a bur and the screw was exposed. A Nance appliance was fabricated over the same screw using the method described during fabrication of the initial appliance. Meanwhile, brackets were placed in the lower arch. The premolars were distalized to spaces created by distalization using NiTi coil springs. Class II elastics were used when needed. Figures 8,9 and 10 show post treatment extraoral and intraoral views of the patient. Total treatment time was 22 months. For retention, an upper Hawley retainer and a lower 3-3 lingual retainer, which was fabricated from 0.0215, stranded wire (Pentaone, Masel, Bristol, PA, USA) was used. Lateral cephalometric and panoramic radiographs taken at the end of treatment can be seen in Figures 11 and 12 .

The treatment results that were measured

Table 1. Pretreatment, post distalization and post treatment cephalometric values.

\begin{tabular}{|c|c|c|c|}
\hline Cephalometric Variables & Pretreatment & Post Distalization & Post Treatment \\
\hline \multicolumn{4}{|l|}{ Skeletal } \\
\hline SNA & 80.90 & 80.10 & 81.00 \\
\hline SNB & 79.50 & 78.70 & 79.00 \\
\hline ANB & 1.30 & 1.50 & 2.00 \\
\hline Witts Appraisal & 1.00 & -1.00 & -1.00 \\
\hline Sn-GoGn & 25.50 & 24.60 & 24.70 \\
\hline FMA & 20.00 & 18.00 & 18.00 \\
\hline $\mathrm{N}-\mathrm{Me}$ & 113.00 & 108.00 & 111.00 \\
\hline \multicolumn{4}{|l|}{ Dental } \\
\hline U6-SN & 75.00 & 76.00 & 75.00 \\
\hline U6-VR & 33.50 & 30.00 & 29.50 \\
\hline U6-SN (mm) & 71.00 & 69.00 & 69.50 \\
\hline U4-SN & 86.00 & 89.00 & 86.00 \\
\hline U4-VR & 45.00 & 44.00 & 42.00 \\
\hline U4-SN (mm) & 73.00 & 72.00 & 72.50 \\
\hline U1-VR & 61.50 & 60.00 & 59.00 \\
\hline U1-NA (mm) & 4.00 & 4.00 & 4.00 \\
\hline U1-NA () & 18.00 & 16.00 & 19.00 \\
\hline L1-NB (mm) & 1.00 & 4.00 & 3.00 \\
\hline L1-NB() & 22.00 & 27.00 & 27.00 \\
\hline IMPA & 96.00 & 102.00 & 102.00 \\
\hline U1/L1 & 144.00 & 132.00 & 132.00 \\
\hline \multicolumn{4}{|l|}{ Soft Tissue } \\
\hline Ls-E plane & -5.00 & -7.00 & -6.00 \\
\hline Li-E plane & -3.00 & -3.00 & -1.00 \\
\hline Nasolabial angle & 110.00 & 109.00 & 114.00 \\
\hline
\end{tabular}


from the cephalograms are given in Table 1. The maxillary first molars were distalized 3.5 to super Class I molar relationship in 6 months (U6-VR distance). There was $2 \mathrm{~mm}$ intrusion of upper first molars (U6-SN distance). Meanwhile, almost no anterior movement was observed in anchoring first premolars and upper incisor. Since force application was carried out via upper first premolars, slight anterior tipping of $3^{\circ}$ was observed in upper first premolars. Upper incisor angulation was slightly affected by distalization.

Mandibular plane angle decreased $1^{\circ}$ ISN -GoGn) during distalization and this change was still present at the completion of treatment.

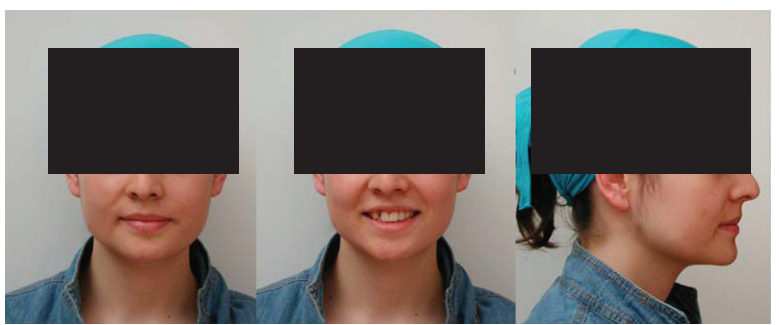

Figure 1. Initial extraoral views of the patient.

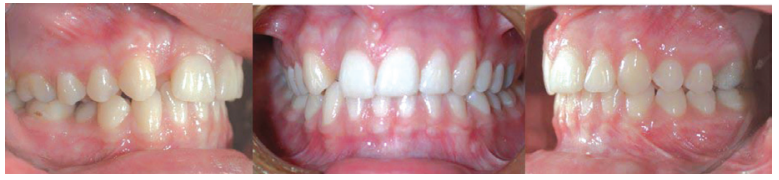

Figure 2. Initial intraoral views of the patient.

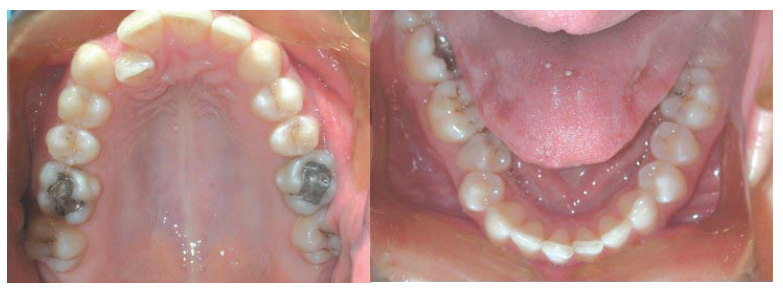

Figure 3. Initial upper and lower occlusal views.

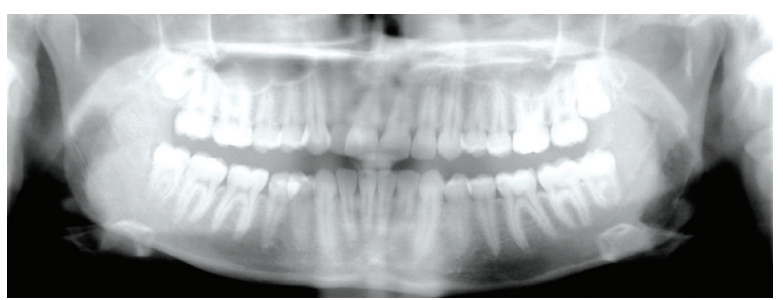

Figure 5. Initial panoramic radiograph.

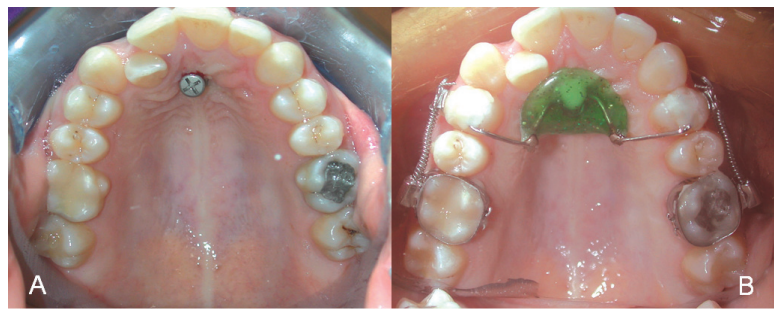

Figure 6. The screw placed and the appliance used for distalization.
Sagittal skeletal positions were not affected with treatment.

Upper lip was slightly retruded and the lower lip retained its position at the end of distalization. Both of the lips showed protrusion during fixed appliance stage.

Total cephalometric superimposition (SellaNasion plane at Sellal and local maxillary superimposition (Anterior Nasal Spine-Posterior Nasal Spine plane at ANS) can be seen in Figures 13 and 14.

Dental cast measurements showed that both of the upper premolars and first molar were rotated distopalatally. Slight expansion was observed in upper first premolar, second premolar and first molar widths (Figure 15) (Table 2).

\section{DISCUSSION}

Despite the successful use of conventional extraoral appliances for years, the need for compliance and their unaesthetic appearance made the need to search for alternatives. The

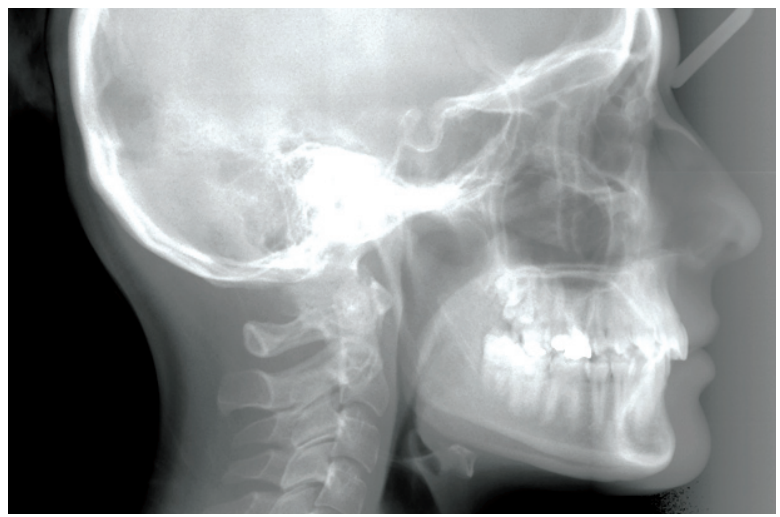

Figure 4. Initial lateral cephalometric radiograph.

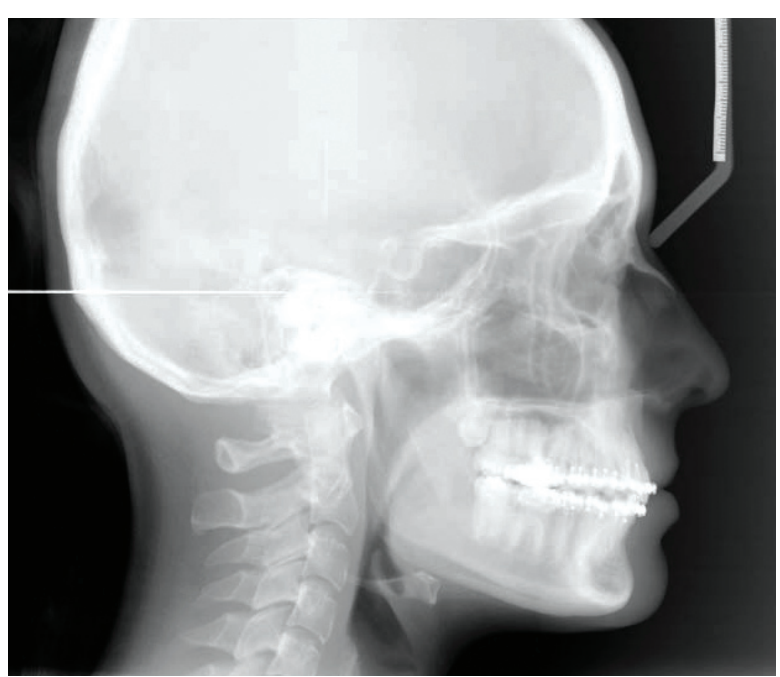

Figure 7. Post distalization lateral cephalometric radiograph. 
introduction of bone anchors in orthodontics has made a revolutionary change in fulfilling this need. Even treatment mechanics that were based on their use were introduced.

Different modifications of implant supported

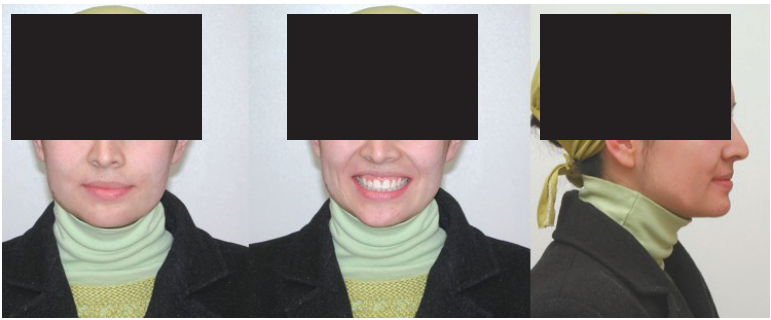

Figure 8. Post treatment extraoral views of the patient.

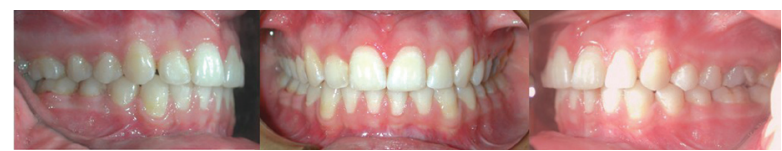

Figure 9. Post treatment intraoral views of the patient.

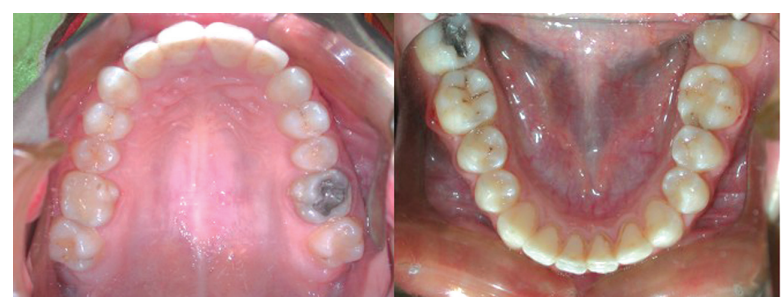

Figure 10. Post treatment upper and lower occlusal views.

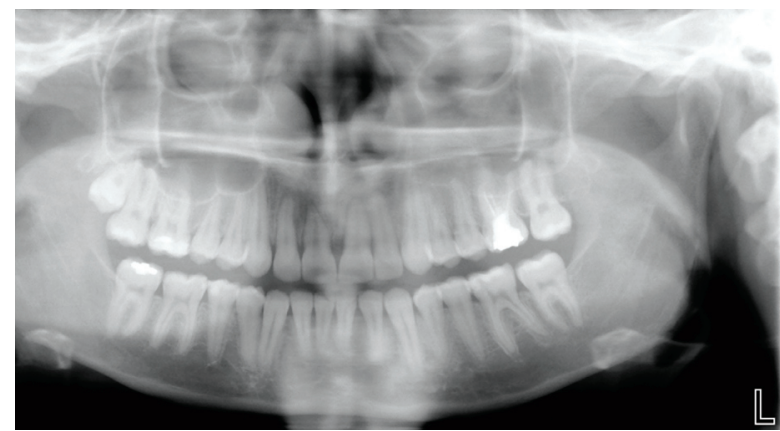

Figure 12. Post treatment panoramic radiograph.

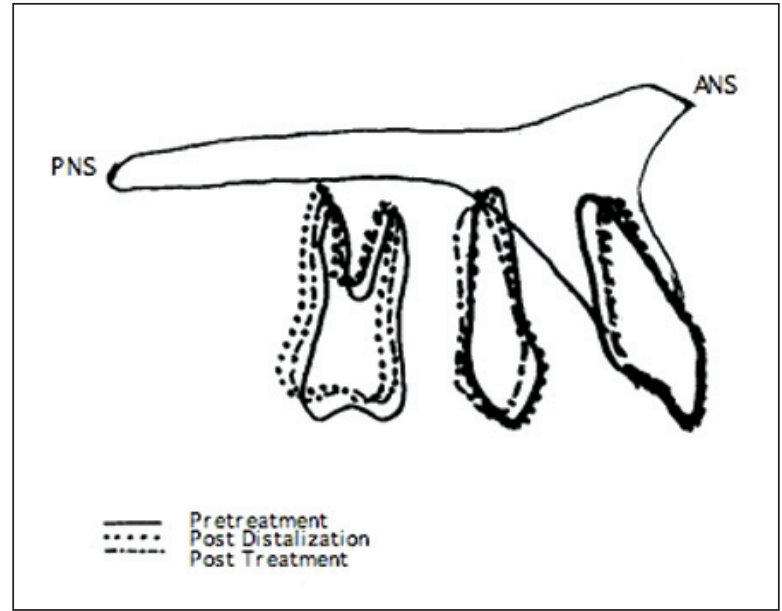

Figure 14. Local maxillary superimposition at ANS-PNS plane. molar distalization appliances were introduced. However a majority of the reports were based on records taken at the end of distalization. Anchorage preservation during retraction of the anterior segment is also quite important since some amount of the space gained is often lost during this stage. In the present case report, treatment result was evaluated both at the end of distalization and at the end of treatment.

Implants can be used as direct units for force application of they can be used to reinforce the anchorage teeth. In this case report, the upper first premolars were secured using a Nance button

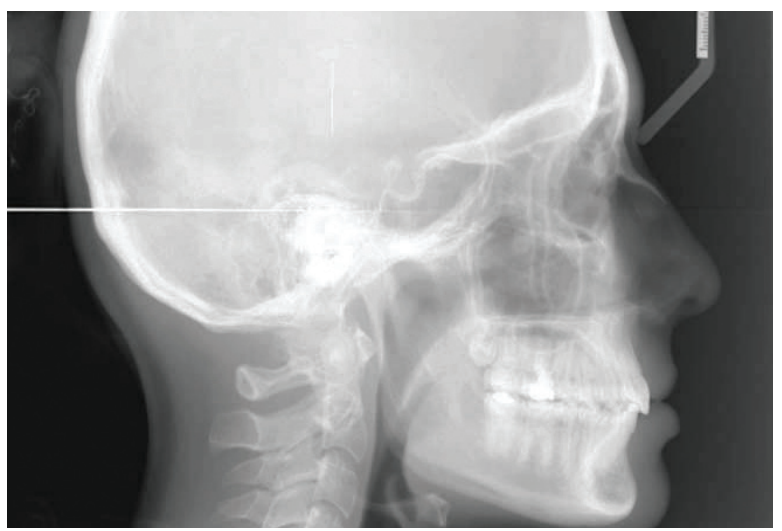

Figure 11. Post treatment lateral cephalometric radiograph.

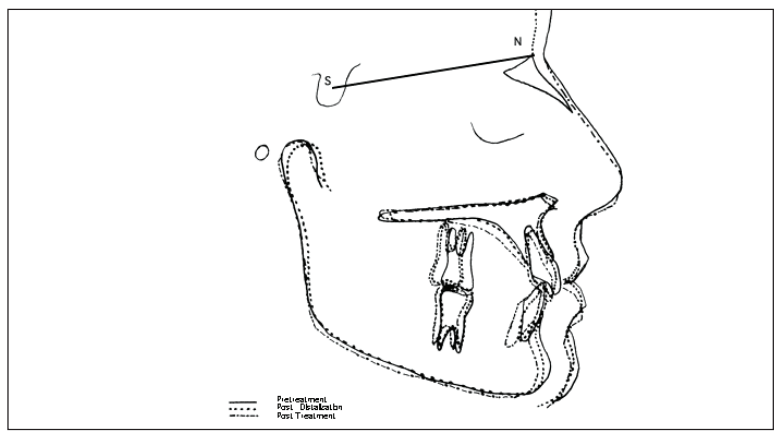

Figure 13. Total superimposition at SN plane.

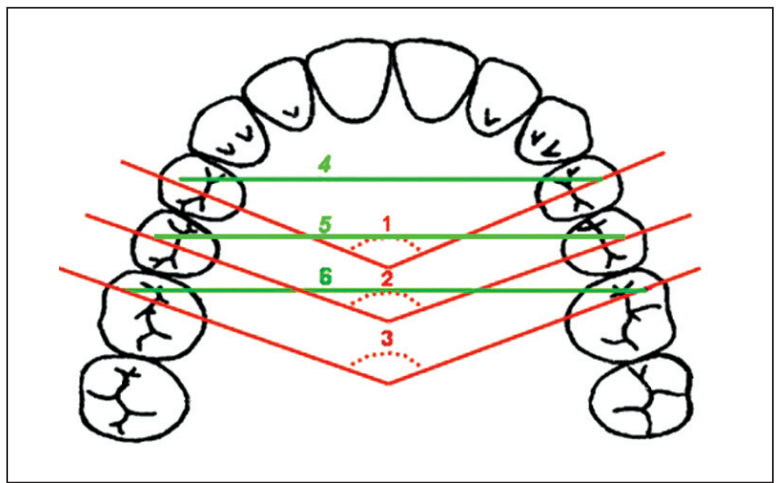

Figure 15. Dental cast measurements: 1. U4 buccopalatal axis/ Mid palatal sture angle, 2. U5 buccopalatal axis/Mid palatal sture angle, 3. U6 buccopalatal axis/Mid palatal sture angle, 4. Right U4 buccal tubercule/ Left U4 buccal tubercule distance, 5 . Right U5 buccal tubercule/ Left U5 buccal tubercule distance, 6 . Right U6 buccal tubercule/ Left U6 buccal tubercule distance. 
to IMF screw that was placed in anterior palatal region. Gelgor et $\mathrm{al}^{4}$ have used a similar appliance for anchorage reinforcement during molar distalization but the forces in their appliance were transmitted directly to the screw, which might cause the failure of the screws. In this case, the screw was not loaded directly; an acrylic button was used to reduce the amount of force that the screw received.

The average amount of molar distalization was $3.5 \mathrm{~mm}$. The rate of distalization was $0.58 \mathrm{~mm}$ per month. Gelgor et al ${ }^{4}$ have also found a similar rate of distalization in their controlled study. Karaman et al, ${ }^{11}$ Kırcelli et $\mathrm{al}^{16}$ and Escobar et al ${ }^{17}$ have also achieved successful distalization results with different appliances that have reinforced their anchorage with the use of a palatally placed screw. The distalization rate found in this case report was also similar to those that were found with conventional intraoral distalization appliances.

Anchoring premolars showed slight anterior tipping. Gelgor et $\mathrm{al}^{4}$ have also reported anterior tipping of $2.84^{\circ}$ in their study. The use of a single screw might have caused this amount of tipping. Several authors that have used palatal screws for distalization have placed two screws and reported less tipping values. ${ }^{16,18}$ Therefore we believe that a single screw is only sufficient for cases that need less amount of distalization.

The placement and removal of the screws are quite easy and well tolerated by the patients. One major drawback of this kind of appliance is the need for removal of the appliance after distalization of second premolars. The appliance should be replaced with a nance button or a transpalatal arch to free the first premolars and during anterior retraction, if needed. However if a clinician aims to use the same implant supported appliance during incisor retraction, an osseointegrated implant or a zygoma anchorage will be the appliance of choice.

Minor irritation of the palatal mucosa was observed after the removal of the appliance. This kind of irritation was also reported with the use of a pendulum appliance and a nance button. This situation can be prevented with maintenance of optimum oral hygiene.

\section{CONCLUSIONS}

Successful distalization of maxillary molars was achieved in 6 months. Only a small amount of mesial tipping was observed in anchoring premolars. The total treatment time was also optimum for this patient. The ease in placement and removal, the possibility of immediate loading and positive toleration of the appliance by the patient are the main advantages of the appliance. However, long term evaluation after removal of all of the appliances should be made with a controlled clinical study.

Table 2. Pretreatment, post distalization and post treatment dental cast measurements.

\begin{tabular}{l|cc}
\hline & Pretreatment & Posttreatment \\
\hline U4 buccopalatal axis/Mid palatal sture & 73 & 76 \\
\hline U5 buccopalatal axis/Midpalatal sture & 76 & 78 \\
\hline U6 buccopalatal axis/Midpalatal sture & & 65 \\
\hline Right U4 bt/ Left U4 bt & 62 & 41.5 \\
\hline Right U5 bt/ Left U5 bt & 38.5 & 45.5 \\
\hline
\end{tabular}




\section{REFERENCES}

1. Melsen B, Verna C. A rational approach to orthodontic anchorage. Prog Orthod 1999;1:10-22.

2. Higuchi KW, Slack JM. The use of titanium fixtures for intraoral anchorage to facilitate orthodontic tooth movement. Int J Oral Maxillofac Implants 1991;6:338-344.

3. Cheng SJ, Tseng IY, Lee JJ, Kok SH. A prospective study of the risk factors associated with failure of mini-implants used for orthodontic anchorage. Int $J$ Oral Maxillofac Implants 2004;19:100-106.

4. Gelgor IE, Buyukyilmaz T, Karaman Al, Dolanmaz D, Kalayci A. Intraosseous screw-supported upper molar distalization. Angle Orthod 2004;74:838-850.

5. Roberts WE, Smith RK, Silberman Y, Mozsary PG, Smith RS. Osseous adaptation to continuous loading of rigid endosseous implants. Am J Orthod 1984;86:95-111.

6. Roberts WE, Marshall KJ, Mozsary P. Rigid endosseous implant utilized as anchorage to protract molars and close atrophic extraction site. Angle Orthod 1990;60:135152.

7. Diedrich PR, Fuhrmann RA, Wehrbein $H$, Erpenstein H. Distal movement of premolars to provide posterior abutments for missing molars. Am J Orthod Dentofacial Orthop 1996;109:355-360.

8. Roberts WE, Arbuckle GR, Analoui M. Rate of mesial translation of mandibular molars using implant-anchored mechanics. Angle Orthod 1996;66:331-338.

9. Wehrbein $H$, Feifel $H$, Diedrich P. Palatal implant anchorage reinforcement of posterior teeth: a prospective study. Am J Orthod Dentofacial Orthop 1999;116:678-686.

10. Block MS, Hoffman DR. A new device for absolute anchorage for orthodontics. Am J Orthod Dentofacial Orthop 1995; 107:251-258.

11. Karaman Al, Basciftci FA, Polat O. Unilateral distal molar movement with an implant-supported distal jet appliance. Angle Orthod 2002;72:167-174.

12. Ödman J, Lekholm U, Jemt T, Brånemark PI, Thilander B. Osseointegrated titanium implants-a new approach in orthodontic treatment. Eur J Orthod 1988;10:98-105.

13. Gedrange T, Kobel C, Harzer W. Hard palate deformation in an animal model following quasi-static loading to stimulate that of orthodontic anchorage implants. Eur $J$ Orthod 2001;23:349-354.

14. Creekmore TD, Eklund MK. The possibility of skeletal anchorage. J Clin Orthod 1983;17:266-269.

15. Byloff FK, Kärcher H, Clar E, Stoff F. An implant to eliminate anchorage loss during molar distalization: a case report involving the Graz implant-supported pendulum. Int J Adult Orthod Orthognath Surg 2000;15:129137.
16. Kircelli BH, Zafer OP, Kircelli C. Maxillary molar distalization with a bone-anchoraged pendulum appliance. Angle Orthod 2005;76:650-659.

17. Escobar SA, Tellez PA, Moncada CA, Villegas CA, Latorre CM, Oberti $G$. Distalization of maxillary molars with the bonesupported pendulum: a clinical study. Am J Orthod Dentofac Orthop 2007;131:545-549.

18. Polat-Ozsoy O, Kırcelli BH, Arman-Özçırpıcı A, Pektaș ZÖ, Uçkan S. Pendulum springs with different anchorage designs: conventional anchorage vs bone anchorage. $\mathrm{Am}$ J Orthod Dentofac Orthop (in press). 